\title{
Post-Vehicle-Application Lithium-Ion Battery Remanufacturing, Repurposing and Recycling Capacity: Modeling and Analysis
}

\author{
Charles Robert Standridge ${ }^{1}$, Md Mehedi Hasan ${ }^{2}$ \\ ${ }^{1}$ Grand Valley State University (United States) \\ ${ }^{2}$ Steelcase (United States) \\ standri@g,gvsu.edu, hasanm@,mail.gvsu.edu
}

Received: January 2015

Accepted: May 2015

\section{Abstract:}

Purpose: A mathematical model is used to help determine the manufacturing capacity needed to support post-vehicle-application remanufacturing, repurposing, and recycling of lithium-ion batteries over time. Simulation is used in solving the model to estimate capacity in $\mathrm{kWh}$. Lithium-ion batteries that are commonly used in the electrification of vehicles cannot be simply discarded post-vehicle-application due to the materials of which they are composed. Eventually, each will fail to hold a charge and will need to be recycled. Remanufacturing, allowing a battery to return to a vehicle application, and repurposing, transforming a battery for use in a nonvehicle application, postpone recycling and increase value.

The mathematical model and its solution using simulation test the hypothesis that the capacity needed for remanufacturing, repurposing, and recycling as well as new battery production is a function of a single parameter: the percent of post-vehicle-application batteries that are remanufactured.

Design/methodology/approach: Equations in the mathematical model represent the capacity needed for remanufacturing, repurposing, and recycling as well as new battery production as dependent variables. Independent variables are exogenous quantities as such as the demand for electrified vehicles of all types, physical properties of batteries such as their 
application life distribution including the time to recycling, and a single decision variable: the percent of post-vehicle-application batteries that are remanufactured. Values of the dependent variables over time are estimated by simulation for values of the percent of post-vehicleapplication batteries ranging from $0 \%$ to $85 \%$ in steps of $5 \%$.

Findings: The simulation results support important insights for investment in capacity for remanufacturing, repurposing, and recycling of post-vehicle-application batteries as well as new batteries. The capacity needed for recycling is relatively constant regardless of the percent of post-vehicle-application batteries that are remanufactured. The sum of the capacity for remanufacturing and recycling is relatively constant as well. The need for new battery production capacity is reduced significantly $(>10 \%)$ for remanufacturing percentages of $55 \%$ and above.

Research limitations/implications: There is a high degree of uncertainty associated with any forecast concerning post-vehicle-application lithium-ion batteries due to a lack of experience with their remanufacturing, repurposing, and recycling.

Practical implications: Electrification of vehicles appears to be the only technically feasible approach to meeting government regulations concerning mileage and emissions (Center for Climate and Energy Solutions 2013). The planning in the present for the remanufacturing, repurposing, and recycling of the lithium-ion batteries used in electrification of vehicles is necessary. Capacity estimation is one important component of such planning.

Social implications: The electrification of vehicles versus the use of fossil fuels is consistent with the guiding principles of sustainability in helping to meet current needs without compromising the needs and resources of future generations. Reusing entire lithium-ion batteries or recycling the materials of which they are composed further reinforces the sustainability of vehicle electrification.

Originality/value: Estimates of recycling capacity needed in 2030, about 2.69M kWh, change little with the percent of post-vehicle-application batteries that are remanufactured. The need for significant recycling capacity appears between 2022 and 2024, increasing steadily thereafter. Similarly, the sum of remanufacturing and repurposing capacity is relatively constant indicating the need for flexible facilities that can do either task. In addition by 2030, up to approximately $25 \%$ of new battery production could be replaced by remanufactured batteries.

Keywords: lithium-ion batteries, recycling, remanufacturing, repurposing, forecasting, mathematical modeling, simulation 


\section{Introduction}

Post-vehicle-application lithium-ion batteries can no longer hold a sufficient charge to meet regulatory standards for use in the power-train of moving vehicles such as hybrid electric cars and buses. A lithium-ion battery is a collection of lithium-ion cells that work together through electrical wiring and a control board.

Foster, Isely, Standridge and Hasan (2014) as well as Standridge and Corneal (2014) discuss three possible ways of further using such batteries as well as providing an extensive literature review:

- Remanufacturing for intended reuse in vehicles. Replacement of damaged cells within the battery shows promises as an effective remanufacturing strategy.

- Repurposing by reengineering a battery for a non-vehicle, stationary storage application. This usually means reconfiguring the cells comprising the battery and developing a different control system as well as repairing any damage as in remanufacturing.

- Recycling that is disassembling each cell in the battery and safely extracting the precious metals, chemicals and other bi-products, which are sold on the commodities market or re-introduced into a battery manufacturing process. Recycling is limited to cells that are no longer suitable for remanufacturing or repurposing applications. Eventually, each cell will need to be recycled.

Furthermore, Foster et al. (2014) present a simple model which transforms existing forecasts of the number of electric vehicles and plug-in hybrid electric vehicles into the number of postvehicle-application batteries. In addition, these authors present cost-benefit analyzes showing that remanufacturing is more economical than repurposing as well as showing that recycling is not economical. This leads to the conclusion that remanufacturing, repurposing, and recycling must be integrated into a single process for handling post-vehicle-application batteries and that the cost of recycling must be borne by remanufacturing and repurposing applications.

The work of these authors is extended to a full mathematical model to help plan remanufacturing, repurposing, and recycling production capacity, as well as new battery production capacity, given any forecast of the number of electric vehicles and plug-in hybrid electric vehicles. The equations comprising the model are evaluated using simulation. Results estimate the needed capacity over time for various values of a single parameter: the percent of post-vehicle-application batteries that are remanufactured. 


\section{Literature Review}

Foster et al. (2014) as well as Standridge and Corneal (2014) present a comprehensive literature review concerning the processing of post-vehicle-application lithium-ion batteries. Thus, the following discussion is limited to the literature used in developing the capacity planning mathematical model and specifically the development of the forecast of the vehicleapplication lithium-ion battery volume that is input to the model.

Baum (2013) identifies multiple types of hybrid electric vehicles: micro hybrids, mild hybrids, full hybrids, plug-in electric vehicles, and electric vehicles. Micro hybrids offer only start/stop technology that turns the engine off when the car is stopped and restarts the engine when the gas pedal is again depressed. Full hybrids provide both gasoline and electrical systems to power a vehicle. Mild hybrids have technology between that in micro and full hybrids.

In addition, Baum provides a forecast of the number of vehicles in each category, except for micro-hybrids, produced in each year from 2013 through 2017 based on actual production data from 2009 through 2012. Furthermore, the Center for Automotive Research (2009) produced a forecasting model for the total number of electric vehicles of all types. Thus, the number of micro-hybrids can be computed by subtraction using both forecasts.

Hybrid vehicle batteries will have different energy capacities measured in watt-hours. Thus, the capacity planning model will use watt-hours as measure of capacity instead of the number of batteries. Pesaran (2011) gives a range for the energy of each type of electric vehicle which can used to convert number of vehicles into energy expressed in watt-hours.

Battery life impacts the number of post-vehicle-application lithium-ion batteries. Information provided by Smith, Earleywine, Wood and Pesaran (2011) is used to estimate the distribution of battery life for use in the capacity planning model. The distribution is generated by computing battery life for various combinations of daily driving distances and charge/discharge history. Results are given in the form of a histogram.

In general forecasting has to do with using a mathematical model to extrapolate historical data forward in time to make predictions regarding future values of the same quantities. In this case, producing a capacity forecast requires extending in time, combining, and rectifying data from the multiple sources identified above for input to the mathematical model. Caution is in order in drawing conclusions from a forecast based on such data. Primarily there is little experience with customer demand for all types of electrified vehicles as well as the life span, post-vehicle-application potential, and energy range of vehicle-application lithium ion batteries. Thus, there is a great deal of uncertainty associated with the values of the model input data which implies that there is a great deal of uncertainty associated with the capacity values produced by simulating the model. Thus, conclusions have to do with the relationships between the quantities estimated by the simulation instead of the magnitude of these 
quantities. Experience has shown that such relationships are less impacted by uncertainty in model input data than are magnitudes of estimated quantities.

\section{Methods}

The mathematical model is described as well as the computations that produced the forecast of the vehicle-application lithium-ion batteries in watt-hours that is input to the model.

\subsection{The Capacity Planning Model}

The capacity planning model transfers a forecast of the demand for electric hybrid vehicles of all types into an estimate of the production capacity needed for remanufacturing, repurposing, and recycling post-vehicle-application lithium-ion batteries as well as that needed for new batteries. The single model parameter is the percent of such batteries that are remanufactured. The percent of batteries that are recycled is viewed as a physical constraint on the life of the batteries. The batteries that are not remanufactured and still can hold a charge are available for repurposing.

The variables used in the model are defined in Table 1.

At each point in time, the demand for hybrid electric vehicles results in the demand for batteries which may be either new batteries or remanufactured batteries. New batteries are manufactured to make up the difference between the demand and the number of remanufactured post-vehicle-application batteries as shown in Equation 1.

$$
\text { New }_{t}=\text { Demand }_{t}-\text { Remanufactured }_{t}
$$

The three primary equations in the model determine the number of post-vehicle-application batteries that are remanufactured, repurposed, and recycled at a point in time. Note that the index $i$ represents the year a vehicle, remanufacturing, or repurposing application began. The index $j$ has to do with battery life in years which equals $i-(t-M a x L i f e)+1$. The summation is over the values of $i$ only. 


\begin{tabular}{|c|c|}
\hline Variable Name & Definition \\
\hline Demand $_{t}$ & The demand for hybrid electric vehicle batteries at time $t$ in watt-hours \\
\hline $\mathrm{NeW}_{t}$ & The production of new batteries at time $t$ in watt-hours \\
\hline Remanufactured $t$ & Remanufactured post-vehicle-application batteries at time $t$ in watt-hours \\
\hline Repurposed & Repurposed post-vehicle-application batteries at time $t$ in watt-hours \\
\hline Recycled $_{t}$ & Recycled post-vehicle-application batteries at time $t$ in watt-hours \\
\hline MaxLife & The maximum number of years of vehicle application life of a new battery \\
\hline LifeDist(j) & $\begin{array}{l}\text { The percent of new batteries that have a vehicle application life of exactly } j \text { years; } \\
j=1, \ldots, \text { MaxLife }\end{array}$ \\
\hline LifeDistReman(j) & $\begin{array}{l}\text { The percent of remanufactured batteries that have a vehicle application of exactly } j \\
\text { years; } j=1, \ldots \text {, MaxLife }\end{array}$ \\
\hline LifeDistRepurposed(j) & $\begin{array}{l}\text { The percent of repurposed batteries that have a vehicle application of exactly } j \text { years; } \\
j=1, \ldots, \text { MaxLife }\end{array}$ \\
\hline $\operatorname{RemanNewPercent}_{t}(j)$ & $\begin{array}{l}\text { The percent of new batteries at the end of vehicle application life of exactly } j \text { years } \\
\text { that are remanufactured at time } t ; j=1, \ldots, \text { MaxLife }\end{array}$ \\
\hline RepurposedNewPercent $t_{t}(j)$ & $\begin{array}{l}\text { The percent of new batteries at the end of vehicle application life of exactly } j \text { years } \\
\text { that are repurposed at time } t ; j=1, \ldots, \text { MaxLife }\end{array}$ \\
\hline RecycledNewPercent $_{t}(j)$ & $\begin{array}{l}\text { The percent of new batteries at the end of vehicle application life of exactly } j \text { years } \\
\text { that are recycled at time } t ; j=1, \ldots, \text { MaxLife }\end{array}$ \\
\hline RemanPrevPercent $_{t}(j)$ & $\begin{array}{l}\text { The percent of batteries originally remanufactured after } j \text { years of vehicle application } \\
\text { again at the end of vehicle application life that are again remanufactured at time } t\end{array}$ \\
\hline RepurposedPrevPercent $t_{t}(j)$ & $\begin{array}{l}\text { The percent of batteries originally repurposed after } j \text { years of vehicle application at } \\
\text { the end of repurposing application life that are again repurposed at time } t\end{array}$ \\
\hline $\operatorname{Repur}^{2} \operatorname{Recycled}_{t}(j)$ & $\begin{array}{l}\text { The percent of batteries originally repurposed after } j \text { years of vehicle application at } \\
\text { the end of repurposing application life that are recycled at time } t\end{array}$ \\
\hline $\operatorname{Reman}_{2 \operatorname{Recycled}}(j)$ & $\begin{array}{l}\text { The percent of batteries originally remanufactured after } j \text { years of vehicle application } \\
\text { at the end of vehicle application life that are recycled at time } t\end{array}$ \\
\hline
\end{tabular}

Table 1. Capacity Planning Model Variables

$$
\begin{aligned}
& \text { Remanufactured }_{t}=\sum_{i=t-\text { MaxLife }_{\text {fem }}}^{t-1} \operatorname{New}_{i} * \operatorname{LifeDist}_{(j)} * \operatorname{RemanNewPercent}_{t}(j)+ \\
& \operatorname{Remanufactured}_{i} * \operatorname{LifeDistReman}_{(j)} * \\
& \operatorname{RemanPrevPercent}_{t}(j)
\end{aligned}
$$

$$
\begin{aligned}
& \text { Repurposed }_{t}=\sum_{i=t-M a x L i f e}^{t-1} \text { New }_{i} * \operatorname{LifeDist}(j) * \operatorname{RepurposedNewPercent}_{t}(j)+ \\
& \text { Repurposed }_{i} * \text { LifeDistRepurposed }(j) * \\
& \text { RepurposedPrevPercent }_{t}(j) \\
& \text { Recycled }_{t}=\sum_{i=t-M a x L i f e}^{t-1} N e w_{i} * \operatorname{LifeDist}(j) * \operatorname{RecycledNewPercent}_{t}(j)+ \\
& \text { Repurposed }_{i} * \text { LifeDistRepurposed }(j) * \\
& \text { Repur } 2 \text { Recyled }_{t}(j)+ \\
& \text { Remanufactured }_{i} * \text { LifeDistReman }(j) * \\
& \text { Reman } 2 \text { Recyled }_{t}(j)
\end{aligned}
$$

The following should be noted regarding Equations 2-4.

- Substituting Equation 1 into Equation 2 results in an equation expressing remanufactured batteries at time $t$ as a function of remanufactured batteries in prior years as well as the demand in prior years but not as a function of new battery production. 
- Substituting Equation 1 into Equation 3 results in an equation expressing repurposed batteries at time $t$ as a function of remanufactured and repurposed batteries in prior years as well as the demand in prior years but not as a function of new battery production.

- Substituting Equation 1 into Equation 4 results in an equation expressing recycled batteries at time $t$ as a function of remanufactured and repurposed batteries in prior years as well as the demand in prior years but not as a function of new battery production.

- Thus, new battery production capacity is an output of the model, not an input to the model, as are remanufacturing, repurposing, and recycling capacity.

Equation 5 shows the relationship between the percent of batteries that are remanufactured, repurposed, and recycled.

$$
\operatorname{RemanNewPercent}_{t}(j)+\operatorname{RepurposedNewPercent}_{t}(j)+\operatorname{RecycledNewPercent}_{t}(j)=1
$$

Equation 5 states that all post-vehicle-application batteries are either remanufactured, repurposed, or recycled. The percent recycled quantifies a physical property: some cells in a post-vehicle-application or repurposed application battery can no longer hold a charge and must be recycled. The percent remanufactured is the model parameter. By Equation 5, the percent repurposed can be computed.

\subsection{Assumptions and Model Constants}

As the electrification of vehicles is relatively new, there is little experience with post-vehicle-application lithium-ion battery remanufacturing and repurposing particularly regarding the maximum life of batteries in these applications (Foster et al., 2014; Standridge \& Corneal, 2014). Smith et al. (2011) estimate the overall life distribution of lithium-ion batteries for vehicles as having a $95^{\text {th }}$ percentile of 13.2 years and a maximum of $16-17$ years. The designed vehicle application life for a new lithium-ion battery for the Chevy Volt is 8 years (GM-Volt.com, 2011). Marano, Onori, Guezennec, Rizzoni and Madella (2009) independently estimated the same life expectancy as 10 years.

The following model assumptions were based on this information.

- The maximum life of a battery (MaxLife) was set to 15 years about midway between the $95^{\text {th }}$ percentile and the maximum life estimations.

- A battery will have life for remanufacturing and repurposing applications as the maximum life is greater than the designed vehicle application life. 
- End-of-repurposing-life batteries must all be recycled. A stationary storage repurposing application has fewer charge-discharge cycles than a vehicle application. Thus, lithium-ion batteries are premised to last in such applications until unable to hold a charge $\left(\operatorname{RepurposedPrevPercent}_{t}(j)=0\right.$ and $\operatorname{Repur}_{2} \operatorname{Recycled}_{t}(j)=100 \%$ for all $t$ and $\left.j\right)$. In addition, this implies that an end-of-repurposing application battery cannot be remanufactured for use in a vehicle.

- End-of-remanufacturing-life batteries may be remanufactured a second time or recycled. Our experience with remanufactured batteries is that they display the same performance and thus the same life characteristics as new batteries. Furthermore, the designed vehicle application life is about one half to two thirds of the maximum life. Thus, a constraint that a battery can be remanufactured at most two times before recycling is reasonable and conservative (RemanPrevPercentt $(j)=0$ and Reman 2 Recycledt $(j)=100 \%$ for all $t$ and $j$ if the battery was previously remanufactured). This assumption also implies that no remanufactured battery will be repurposed post-vehicle-application. The result of this constraint is that new battery production will increase in value in the model.

Equation 6 shows an end-of-remanufacturing-life battery must be either repurposed or recycled.

$$
\operatorname{RemanPrevPercent}_{t}(j)+\operatorname{Reman}_{2 \operatorname{Recycled}}(j)=1
$$

Thus, it is sufficient to set the percent of end-of-remanufacturing-life batteries that are remanufactured again taking into a count the span of vehicle application life as new batteries and as remanufactured batteries, equivalent to the $t$ and $j$ indices. There is no recorded experience with such batteries. Therefore, it was assumed that the older the battery the less likely the battery could be used in a remanufacturing application, which seems reasonable. Thus, the percent remanufactured was reduced by $5 \%$ for each year of battery life as shown in Equation 7.

$$
\text { RemanPrevPercent }=\max (1-(\text { Years New }+ \text { Years Remanufactured }) / 10,0)
$$




\subsection{Battery Life Distribution}

The battery life distribution in histogram form computed by Smith, Earleywine, Wood, and Pesaran (2011) was fit to a gamma distribution with parameters $\alpha=39.072$ and $\beta=0.267$. The percent points and mean reported by these authors are compared to the same quantities of the gamma distribution in Table 2 .

\begin{tabular}{|c|c|c|}
\hline Quantity & From Histogram & Gamma Distribution \\
\hline Mean & 10.4 & 10.4 \\
\hline $5^{\text {th }}$ percent point & 7.8 & 7.8 \\
\hline $95^{\text {th }}$ percent point & 13.2 & 13.4 \\
\hline
\end{tabular}

Table 2. Comparison of Histogram with Gamma Distribution of Battery Life

The mean and $5^{\text {th }}$ percent point are the same. The $95^{\text {th }}$ percent point of the gamma distribution is 0.2 greater $(1.5 \%)$. The gamma distribution was used to model battery life.

There is little experience with the life of remanufactured and repurposed batteries. There is no information that indicates that remanufacturing or repurposing changes the life distribution of a battery. Thus, the life distribution following remanufacturing and repurposing is modeled as being the same, LifeDistReman $(j)=\operatorname{LifeDistRepurposed}(j)$ for all $j$.

This single life distribution is computed from the battery life distribution as a conditional distribution depending on the number of years of vehicle application, $v$, and the total application life of the battery (vehicle application + remanufacturing or repurposing application, $u$ ). This conditional distribution is shown in Equation 8, which is written in the form given in Devore (2015).

$$
P(\text { Life }>u \mid \text { Life }>v)=\frac{P(\text { Life }>v \cap \text { Life }>u)}{P(\text { Life }>v)}=\frac{P(\text { Life }>u)}{P(\text { Life }>v)}
$$

\subsection{Vehicle Forecasts and Conversion to Energy}

\begin{tabular}{|c|c|c|c|}
\hline Vehicle Type & Intercept & Slope & R2 \\
\hline Regular Hybrid & 60.9 & +142.83 & 0.9081 \\
\hline Mild Hybrid & 4.5 & +29.42 & 0.8106 \\
\hline Plug-in Hybrid & 18.0 & -38.14 & 0.9638 \\
\hline Full Electric & 15.8 & -32.79 & 0.8972 \\
\hline
\end{tabular}

Table 3. Comparison of Histogram with Gamma Distribution of Battery Life ( $x=$ year-2008) 
As previously discussed, Baum (2013) provides a forecast the number of regular hybrid, mild hybrid, plug-in hybrid, and full electric vehicles through 2017 based on production data from 2009 through 2012. A model was created for each vehicle type by which the forecast could be extended through 2030, the end time of the remanufacturing, repurposing, and recycling capacity plan. This was done using simple regression based on the 8 data points, 2009-2017, provided by Baum. Linear growth is the simplest assumption as data and experience do not exist to support a more complex forecasting procedure. Results are shown in Table 3.

The forecasting model for the total number of electric vehicles of all types produced by the Center for Automotive Research (2009) is given in Equation 9: The number of micro-hybrids can be computed by subtraction from Equation 9 of the equations in Table 3.

$$
\text { Electrified Vehicles }=38.46 *(\text { Year }-1990)+14500
$$

The number of electrified vehicles of each type is shown Table 4.

\begin{tabular}{|l|l|c|c|c|c|c|}
\hline Year & Total & Regular Hybrid & Mild Hybrid & Plug In & Full Electric & Micro Hybrid \\
\hline 2014 & 15423 & 574 & 58 & 75 & 78 & 14638 \\
\hline 2015 & 15462 & 606 & 68 & 97 & 88 & 14603 \\
\hline 2016 & 15500 & 627 & 66 & 109 & 93 & 14605 \\
\hline 2017 & 15538 & 635 & 68 & 113 & 95 & 14627 \\
\hline 2018 & 15577 & 752 & 75 & 142 & 125 & 14484 \\
\hline 2019 & 15615 & 813 & 79 & 160 & 140 & 14423 \\
\hline 2020 & 15654 & 874 & 84 & 178 & 156 & 14362 \\
\hline 2021 & 15692 & 935 & 88 & 196 & 172 & 14302 \\
\hline 2022 & 15731 & 995 & 93 & 214 & 188 & 14241 \\
\hline 2023 & 15769 & 1056 & 97 & 232 & 203 & 14180 \\
\hline 2024 & 15808 & 1117 & 102 & 250 & 219 & 14120 \\
\hline 2025 & 15846 & 1178 & 106 & 268 & 235 & 14059 \\
\hline 2026 & 15885 & 1239 & 111 & 286 & 251 & 13998 \\
\hline 2027 & 15923 & 1300 & 115 & 304 & 266 & 13938 \\
\hline 2028 & 15961 & 1361 & 120 & 322 & 282 & 13877 \\
\hline 2029 & 16000 & 1422 & 124 & 340 & 298 & 13816 \\
\hline 2030 & 16038 & 1483 & 129 & 358 & 314 & 13755 \\
\hline
\end{tabular}

Table 4. Count of Electrified Vehicles by Type (In Thousands)

Note that the number of micro-hybrid vehicles is declining slightly over time as the numbers of the each of the other vehicle types increases.

Table 5 shows the average power in the battery in each type of electrified vehicle as given by Pesaran (2011). 


\begin{tabular}{|c|c|}
\hline Vehicle Type & Power in $\mathbf{W h}$ \\
\hline Regular Hybrid & 135 \\
\hline Mild Hybrid & 52.5 \\
\hline Plug In & 10000 \\
\hline Full Electric & 30000 \\
\hline Micro Hybrid & 20 \\
\hline
\end{tabular}

Table 5. Average Battery Power

Multiplying the forecast of the number of electrified vehicles shown in Table 4 by the average power in the battery of each type shown in Table 5 yields the forecast of the amount of battery power by vehicle type shown in Table 6 .

\begin{tabular}{|c|c|c|c|c|c|c|}
\hline Year & Regular Hybrid & Mild Hybrid & Plug In & Full Electric & Micro Hybrid & Total \\
\hline 2014 & 77490 & 3045 & 750000 & 2340000 & 292761 & 3463296 \\
\hline 2015 & 81810 & 3570 & 970000 & 2640000 & 292050 & 3987430 \\
\hline 2016 & 84645 & 3465 & 1090000 & 2790000 & 292099 & 4260209 \\
\hline 2017 & 85725 & 3570 & 1130000 & 2850000 & 292548 & 4361843 \\
\hline 2018 & 101497 & 3916 & 1418570 & 3741420 & 289678 & 5555081 \\
\hline 2019 & 109719 & 4153 & 1598570 & 4213920 & 288464 & 6214825 \\
\hline 2020 & 117940 & 4390 & 1778570 & 4686420 & 287250 & 6874570 \\
\hline 2021 & 126162 & 4627 & 1958570 & 5158920 & 286035 & 7534314 \\
\hline 2022 & 134383 & 4864 & 2138570 & 5631420 & 284821 & 8194059 \\
\hline 2023 & 142605 & 5101 & 2318570 & 6103920 & 283607 & 8853803 \\
\hline 2024 & 150826 & 5338 & 2498570 & 6576420 & 282393 & 9513548 \\
\hline 2025 & 159048 & 5576 & 2678570 & 7048920 & 281179 & 10173292 \\
\hline 2026 & 167269 & 5813 & 2858570 & 7521420 & 279965 & 10833037 \\
\hline 2027 & 175491 & 6050 & 3038570 & 7993920 & 278751 & 11492781 \\
\hline 2028 & 183712 & 6287 & 3218570 & 8466420 & 277537 & 12152526 \\
\hline 2029 & 191934 & 6524 & 3398570 & 8938920 & 276322 & 12812270 \\
\hline 2030 & 200155 & 6761 & 3578570 & 9411420 & 275108 & 13472015 \\
\hline Percent of Total & $1.6 \%$ & $0.1 \%$ & $26.1 \%$ & $68.8 \%$ & $3.5 \%$ & $100.0 \%$ \\
\hline
\end{tabular}

Table 6. Power in Batteries of Electrified Vehicles (in kWh)

Note that almost $95 \%$ of the power in batteries is forecast to be from fully electric and plug in electric vehicles. Also, any impact of any increase in uncertainty due to generating the number of micro hybrids by the subtraction of two other forecasts is greatly reduced in the simulation results as micro hybrids provide only $3.5 \%$ of the total energy capacity. 


\section{Simulation Experimentation and Results}

The simulation experiment design included setting the value of the model parameter: percent remanufactured. Simulation results are obtained for values in the range $[0,85]: 0,5,10, \ldots, 85$ for each of the years 2016 through 2030 . The percent recycled is set to $15 \%$ based on the work of Jody, Daniels, Duranceau, Pomykala and Spangenberger (2010). The percent repurposed is computed using Equation 5.

The model represents the percent remanufactured, the percent repurposed, and the percent recycled as potentially varying over time $(t)$ and vehicle application life $(j)$. As previously discussed, there is little experience with the behavior of remanufactured and repurposed batteries overtime. Thus, the percent remanufactured was set to the same value for all $t$. In addition, it was felt that the percent of batteries needing recycling as well as those capable of being remanufactured for a vehicle application would change in time. The former was assumed to increase and the latter decrease after four years. For this simulation experiment, $5 \%$ was used for both the increase in recycling percent and the decrease in remanufacturing percent. This implies that the repurposing percent remains constant.

The simulation results can be used to in computing verification and validation evidence as discuss by Sargent (2013). One such computation is to show that all demand is met with either new or remanufactured batteries for all years for all values of the percent remanufactured. To illustrate, consider the year 2030 for the percent remanufactured $=50 \%$. The demand is $12,812,270 \mathrm{kWh}$ which is met by $11,669,588 \mathrm{kWh}$ of new batteries and $1,142,681 \mathrm{kWh}$ of remanufactured batteries.

A second such computation is to show that all batteries reaching the end of application life in each year whether new, remanufactured, or repurposed, are subsequently remanufactured, repurposed or recycled. Again to illustrate, consider the year 2030 for the percent remanufactured $=50 \%$. The end of application life batteries total 5,868,232 kWh: new, 5,859,351 kWh; remanufactured, $4573 \mathrm{kWh}$; repurposed, $4308 \mathrm{kWh}$. Of these, 1,142,681 kWh are remanufactured; 2,039,913 kWh are repurposed; and 2,685,637 kWh are recycled.

Table 7 shows how demand is met in 2030 as a function of the percent remanufactured using a combination of new and remanufactured batteries. The demand in 2030 is forecast to be $12,812,270 \mathrm{kWh}$. 


\begin{tabular}{|c|c|c|c|}
\hline $\begin{array}{c}\text { Percent to be } \\
\text { remanufactured }\end{array}$ & $\begin{array}{c}\text { New } \\
\mathbf{k W h})\end{array}$ & $\begin{array}{c}\text { Remanufactured } \\
\mathbf{( k W h )}\end{array}$ & $\begin{array}{c}\text { Percent of demand } \\
\text { from remanufactured }\end{array}$ \\
\hline 0 & $12,812,270$ & 0 & 0 \\
\hline 5 & $12,812,269$ & 1 & 0.0 \\
\hline 10 & $12,812,206$ & 63 & 0.0 \\
\hline 15 & $12,810,876$ & 1,393 & 0.0 \\
\hline 20 & $12,800,065$ & 12,204 & 0.1 \\
\hline 25 & $12,756,185$ & 56,085 & 0.4 \\
\hline 30 & $12,649,101$ & 163,169 & 1.3 \\
\hline 35 & $12,467,430$ & 344,840 & 2.7 \\
\hline 40 & $12,226,453$ & 585,816 & 4.6 \\
\hline 45 & $11,955,320$ & 856,950 & 6.7 \\
\hline 50 & $11,669,588$ & $1,142,681$ & 8.9 \\
\hline 55 & $11,378,504$ & $1,433,766$ & 11.2 \\
\hline 60 & $11,087,534$ & $1,724,736$ & 13.5 \\
\hline 65 & $10,796,677$ & $2,015,592$ & 15.7 \\
\hline 70 & $10,505,935$ & $2,306,335$ & 18.0 \\
\hline 75 & $10,215,306$ & $2,596,963$ & 20.3 \\
\hline 80 & $9,924,791$ & $2,887,478$ & 22.5 \\
\hline 85 & $9,634,390$ & $3,177,879$ & 24.8 \\
\hline 7 & & 1906 & \\
\hline
\end{tabular}

Table 7. New and remanufactured batteries by percent remanufactured -

Simulation results for 2030

Note that for $50 \%$ remanufactured and above, each increase of $5 \%$ in the percent remanufactured yields an increase of $2.2 \%-2.3 \%$ in the percent of demand met by remanufactured batteries up to about $25 \%$ for all available post-vehicle-application batteries remanufactured.

Table 8 shows the repurposing and recycling volume as a function of the percent remanufactured for 2030 . 


\begin{tabular}{|c|c|c|}
\hline $\begin{array}{l}\text { Percent to be } \\
\text { remanufactured }\end{array}$ & $\begin{array}{l}\text { Repurposed } \\
\text { (kWh) }\end{array}$ & $\begin{array}{l}\text { Recycled } \\
\text { (kWh) }\end{array}$ \\
\hline 0 & $3,186,925$ & $2,688,642$ \\
\hline 5 & $3,186,924$ & $2,688,642$ \\
\hline 10 & $3,186,863$ & $2,688,637$ \\
\hline 15 & $3,185,484$ & $2,688,548$ \\
\hline 20 & $3,174,344$ & $2,688,266$ \\
\hline 25 & $3,129,866$ & $2,687,847$ \\
\hline 30 & $3,022,114$ & $2,687,405$ \\
\hline 35 & $2,839,772$ & $2,686,963$ \\
\hline 40 & $2,598,123$ & $2,686,520$ \\
\hline 45 & $2,326,318$ & $2,686,078$ \\
\hline 50 & $2,039,913$ & $2,685,637$ \\
\hline 55 & $1,748,156$ & $2,685,195$ \\
\hline 60 & $1,456,513$ & $2,684,754$ \\
\hline 65 & $1,164,983$ & $2,684,313$ \\
\hline 70 & 873,567 & $2,683,873$ \\
\hline 75 & 582,264 & $2,683,433$ \\
\hline 80 & 291,075 & $2,682,993$ \\
\hline 85 & 0 & $2,682,553$ \\
\hline
\end{tabular}

Table 8. New and remanufactured batteries by percent remanufactured - Simulation results for 2030

Note that the recycled battery volume is nearly constant, varying slightly due to remanufacturing of post-vehicle-application batteries a second time. The repurposed battery volume decreases as the remanufactured battery volume increases as shown in Table 7.

Figure 1 shows the remanufactured battery capacity needed over time for $85 \%$ of post-vehicleapplication batteries remanufactured. Note that the need for recycling capacity becomes significant between 2022 and 2024. 


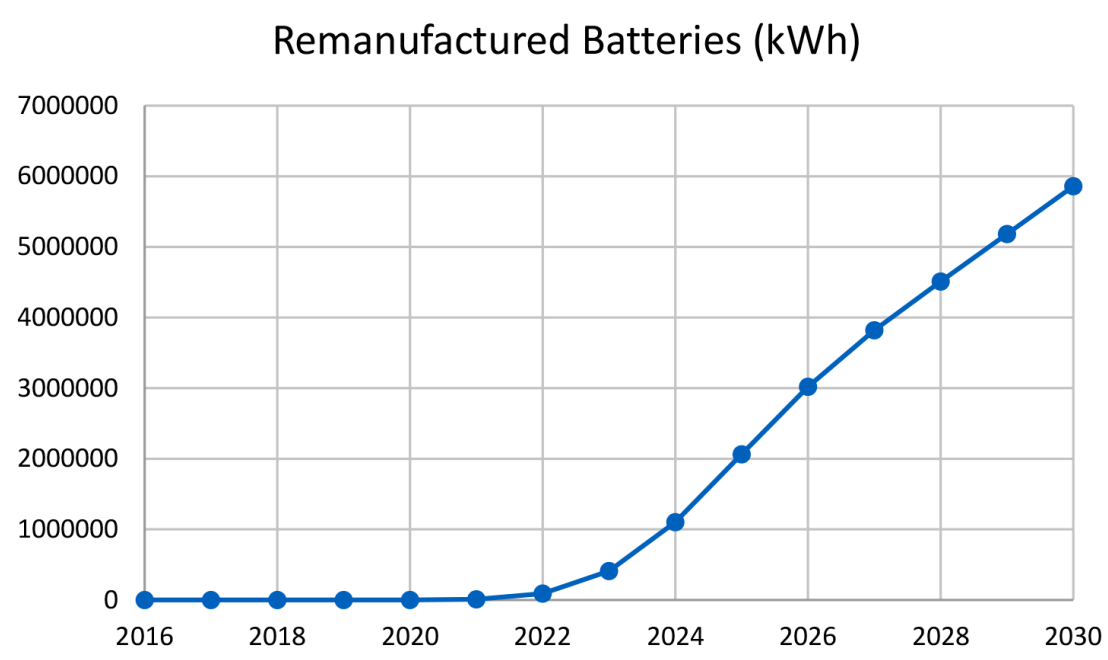

Figure 1. Remanufactured Battery Capacity $(\mathrm{kWh})$ over Time (Percent remanufactured $=85 \%$ )

\section{Conclusions}

The results in Tables 7 and 8 as well as Figure 1 support the following conclusions. A full commitment of all post-vehicle-application batteries to remanufacturing results in an approximate reduction of $25 \%$ in the demand for new batteries by 2030 . Such a commitment is supported by Foster et al. (2014) whose analysis concluded that remanufacturing was more economical than repurposing. Such a commitment means that no post-vehicle-application batteries are available for repurposing applications such as stationary storage.

The capacity needed for repurposing decreases as the percent of post-vehicle-application batteries that are remanufactured increases. However, the sum of the repurposing and remanufacturing capacities is approximately constant on the order of $3.12 \mathrm{M} \mathrm{kWh}$. This is supports the idea of building capacity that is flexible between repurposing and remanufacturing tasks. Based on the discussion in Foster et al. (2014), such flexibility is reasonable to achieve as activities such as battery testing, disassembly, and controller development are common to both repurposing and remanufacturing.

The recycling capacity needed by 2030 , regardless of the percent of post-vehicle-application batteries selected for remanufacturing, is about $2.69 \mathrm{kWh}$, approximately $85 \%$ of the combined repurposing-remanufacturing capacity. Recycling capacity is only $0.23 \%$ less for $85 \%$ of batteries remanufactured than no batteries remanufactured. This shows the small impact of remanufacturing a second time post-vehicle-application batteries that were previously remanufactured. For example in 2030 for the percent of batteries remanufactured equal to $85 \%$, only $0.05 \%$ of the total number of remanufactured batteries were those remanufactured a second time. In addition, the need for recycling becomes significant for the first time between 2022 and 2024 growing steadily over time thereafter. 


\section{Acknowledgments}

The authors acknowledge the Michigan Department of Transportation and the US Department of Transportation via the Mineta National Transit Research Consortium (MNTRC projects \#1137 and \#1238) for their financial support of this work.

\section{References}

Baum, A. (2013). Mild and Micro Hybrids: Moving Forward Albeit Quietly. NextEnergy Energy Storage Event. 30 October.

Center for Automotive Research (2009). The Major Determinants of U.S. Automotive Demand: Factors Driving the U.S. Automotive Market And Their Implications for Specialty Equipment and Performance Aftermarket Suppliers.

http://www.globalautoindustry.com/images/CAR SEMA demand.pdf

Center for Climate and Energy Solutions (2013). Federal Vehicle Standards.

http://www.c2es.org/federal/executive/vehicle-standards

Devore, J.L. (2015). Probability and Statistics for Engineering and the Sciences. Boston, MA: Cengage Learning.

Foster, M., Isely, P, Standridge, C.R., \& Hasan, M.M. (2014). Feasibility assessment of remanufacturing, repurposing, and recycling of end of vehicle application lithium-ion batteries. Journal of Industrial Engineering and Management, 7(3), 698-715.

http://dx.doi.org/10.3926/jiem.939

GM-Volt.com. (2011). Chevy Volt Specs. Retrieved: January 2015. http://gm-volt.com/fullspecifications

Jody, B.J., Daniels, E.J., Duranceau, C.M., Pomykala Jr., J.A., \& Spangenberger. J.S. (2010). End-of-Life Vehicle Recycling: State of the Art of Resource Recovery from Shredder Residue. Center for Transportation Research, Argonne National Laboratory Publication (September). http://www.es.anl.gov/Energy_systems/CRADA_Team/publications/End\%20of\%20life\%20vehicle\%20recycling \%20Technology\%20review.pdf

Marano, V., Onori, S., Guezennec, Y., Rizzoni, G., \& Madella, N. (2009). Lithium-ion batteries life estimation for plug-in hybrid electric vehicles. IEEE Vehicle Power and Propulsion Conference. http://dx.doi.org/10.1109/vppc.2009.5289803

Pesaran, A. (2011). Choices and Requirements of Batteries for EVs, HEVs, PHEVs. National Renewable Energy Laboratory. http://www.nrel.gov/vehiclesandfuels/energystorage/pdfs/51474.pdf

Sargent, R.G. (2013). Verification and validation of simulation models. Journal of Simulation, 7, 12-14. http://dx.doi.org/10.1057/jos.2012.20 
Smith, K., Earleywine, M., Wood, E., \& Pesaran A. (2011). Comparison of battery life across real-world automotive drive-cycles. 7th Lithium Battery Power Conference. 7-8 November. http://www.nrel.gov/docs/fy12osti/53470.pdf

Standridge, C.R., \& Corneal, L. (2014). Remanufacturing, Repurposing, and Recycling of PostVehicle-Application Lithium-ion Batteries, Mineta National Transit Research Center. http://transweb.sjsu.edu/project/1137.html

Journal of Industrial Engineering and Management, 2015 (www.jiem.org)

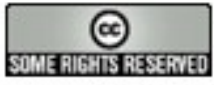

Article's contents are provided on a Attribution-Non Commercial 3.0 Creative commons license. Readers are allowed to copy, distribute and communicate article's contents, provided the author's and Journal of Industrial Engineering and Management's names are included. It must not be used for commercial purposes. To see the complete license contents, please visit http://creativecommons.org/licenses/by-nc/3.0/. 